\title{
Type-1 and Type-2 fuzzy Sets to Control a Nonlinear Dynamic System
}

\author{
Kheir Saadaoui ${ }^{1}$, Brahim Bouderah ${ }^{1}$, Ouarda Assas ${ }^{1}$, Mohammed Abdallah Khodja ${ }^{2,3 *}$ \\ ${ }^{1}$ Department of Mathematics, Laboratory of Pure and Applied Mathematics, Mohamed Boudiaf University of Msila, Msila, \\ 28000, Algeria \\ ${ }^{2}$ Department of Electrical Engineering, Qassim University, P.O.B. 6677, Buraidah, 51452, Saudi Arabia \\ ${ }^{3}$ Department of Electrical Engineering, Mohamed Boudiaf University of Msila, Msila, 28000, Algeria
}

Corresponding Author Email: m.khodja@qu.edu.sa

https://doi.org/10.18280/ria.330101

Received: 3 November 2018

Accepted: 26 January 2019

\section{Keywords:}

type-1 fuzzy sets, interval type-2 fuzzy

sets, nonlinear dynamic system,

PUMA560 robot

\begin{abstract}
This paper is related to the simulation, in Matlab environment, of a robot manipulator controlled by both type- 1 and interval type- 2 fuzzy controllers, in which a modification in Karnik-Mendel algorithm has been proposed. To calculate the output of interval type-2 fuzzy system there is a main step called type-reduced; this operation is based on Karnik-Mendel algorithm, which uses arithmetic mean to calculate the control output. In this work, we propose to change the arithmetic mean by harmonic one. The performances of modified interval type2 controller and type-1 fuzzy controller with and without noises are compared in terms of integral of squared error. The proposed modification in type reduction of Karnik-Mendel algorithm for interval type-2 fuzzy set shows best performance. Indeed, the amount of error in case of modified interval type-2 fuzzy controller is less two times than type- 1 fuzzy controller.
\end{abstract}

\section{INTRODUCTION}

The needing of industrial robot for tasks like cutting and welding, painting and those requiring more precision, obligates many researchers to have well mathematical description and control mastery of this kind of process in order to solve related industrial problems [1-2].

In this context, fuzzy logic theory, introduced firstly by Zadeh [3] has been received more and more attention in both researchers and industrial communities. The main advantage of fuzzy system is that it does not need the knowledge of the system dynamic model. This characteristic is one of the main important features when dealing with nonlinear systems. Moreover, the dynamic modeling of manipulator robot shows a dependence on their dynamical parameters, function of lifetime variations (friction factors affected-by the abuse of joints), and on their dynamical parameters that vary with the completed task [1-2]. These characteristics also give advantage to fuzzy controller on other nonlinear methods as a result of their robustness towards noises affecting the plant [4].

Fuzzy set theory grabs nowadays the attention of many researchers [5-7]. For that, the present paper interests in comparative study between type-1 fuzzy controller and interval type-2 fuzzy controller with modified Karnik-Mendel algorithm applied on PUMA560 robot, and to check what are the differences between them in the studied case. This topic has attracted the attention of many researchers; for instance, Ref. [8] presents hybrid type-1 and interval type-2 fuzzy with PID to control SCARA robot. In [9], optimal interval type-2 fuzzy controller for unmanned underwater vehicle in 3D space was proposed. In [10], the fundamental differences between interval type-2 and type-1 fuzzy logic controllers were detailed. This paper focuses on just on the structure and strategies insight of the both types, but in our work the application of type-1 and interval type-2 fuzzy controller on PUMA560 manipulator robot is performed and the obtained results are compared between them. In [11], the implementation of interval type-2 fuzzy-PID controller is applied on manipulator robot. In [12], a novel development related to an interval type2 fuzzy logic controller for trajectory tracking of a flexible joint manipulator was proposed.

The work presented in this manuscript is the simulation of type-1 fuzzy sets (T1-FS), interval type-2 fuzzy sets (IT2-FS) $[4,7-8]$ and modified type reduction of Karnik-Mendel algorithm used in interval type-2 fuzzy sets (IT2-FS) to control three DOF PUMA560 manipulators; this modification is never proposed before. In fuzzy logic controller designing, 25 fuzzy rules are adopted; the membership functions of input/output variables are symmetric triangles and the input/output scaling factors are chosen by human tuning [7]. We also present a comparative study in terms of integral of squared error (ISE) $[4,8]$ in joint space between the simulated interval-type-2 fuzzy sets and type-1 fuzzy sets counterpart to better appreciate their respective performances in various operating conditions.

\section{MODELING OF PUMA560 ROBOT DYNAMIC}

The dynamic model used for PUMA560 is taken from [9]. Weadopteda robot of three degrees of freedom, and the configuration of space equation is given by:

$$
M(q) \ddot{q}+B(q)[\dot{q} \dot{q}]+C(q)\left[\dot{q}^{2}\right]+G(q)=\Gamma
$$

where:

$M(q)$ : is $3 \times 3$ kinetic energy matrix.

$\left[\dot{q}^{2}\right]: 3 \times 1$ vector given by: $\ddot{q}=\left[\begin{array}{lll}\ddot{q}_{1}, & \ddot{q}_{2}, & \ddot{q}_{3}\end{array}\right]^{T}$ 
$B(q): 3 \times 7$ matrix of Coriolis torques,

$[\dot{q} \dot{q}]: 7 \times 1$ vector of joint velocity products given by:

$[\dot{q} \dot{q}]=\left[\dot{q}_{1} \dot{q}_{2}, \dot{q}_{1} \dot{q}_{3}, 0,0,0, \dot{q}_{2} \dot{q}_{3}, 0\right]^{T}$

$C(q): 3 \times 3$ matrix of centrifugal torques,

$\left[\dot{q}^{2}\right]: 3 \times 1$ vector given by: $\left[\dot{q}^{2}\right]=\left[\dot{q}_{1}^{2}, \dot{q}_{2}{ }^{2}, \dot{q}_{3}{ }^{2}\right]^{T}$,

$G(q)$ : is $3 \times 1$ vector of gravity torques,

$\Gamma$ : is $3 \times 1$ vector of joint torque.

The dynamic parameters of Puma560 are taken from [9], see the Appendix. Simulation control system diagram of PUMA560 is shown in Figure 1. To check the robustness of controller a disturbance torque is applied on the robot and a cycloid trajectory test is performed. Recall that only three links of PUMA560 robot are used in this work. The three degrees of freedom PUMA560 robot has the same configuration space equation general form as in [9] 6-DOF, in which the last three joints $q_{4}, q_{5}$ and $q_{6}$ are set to zero in equation cited in [9] so they keep their initial states while the robot is moving.

We can define a general equation that allows us to use PUMA560 robot as a 3-DOF robot and its general control system represented in Figure 1.

Note: All parameters and Matrix in (1) are taken from paper [9], just replace $q_{4}, q_{5}$ and $q_{6}$ by zero and do simplification to get 3-DOF PUMA560 robot as in equation (1).

\section{CONTROLLERTYPE-1 FUZZY SETS}

The basic scheme of a fuzzy controller [10] is shown in Figure 2. Fuzzy controller has four parts; the first one is the fuzzification, which changes the crisp values to fuzzy values and determines membership degrees of the chosen PD, which needs two inputs, error and its change, and one output as control signal. The position errors and their variations and the control signal are quantized into five sets as in Figure3 represented by a set of linguistic variables with triangle membership functions with $[-1,1]$ as universe of discourse [45, 13]:

NegativeLarge (N-L), NegativeSmall (N-S), zero (Ze), PositiveSmall (P-S) and PositiveLarge (P-L).

We choose the output as singletons values $[\mathrm{N}-\mathrm{L} ; \mathrm{N}-\mathrm{S}$; Ze; $\mathrm{P}-\mathrm{S} ; \mathrm{P}-\mathrm{L}]=[-1 ;-0.5 ; 0 ; 0.5 ; 1]$

The second part is the inference, which cannot function without rule base like that shown in Table 1 [7]. The max-min Mamdani fuzzy inference system [10] was adopted for our controller. The last part is the defuzzification, in which the fuzzy inference result is changed to crisp value. There are many methods for defuzzification; in our work centroid of area is chosen $[4,10]$.

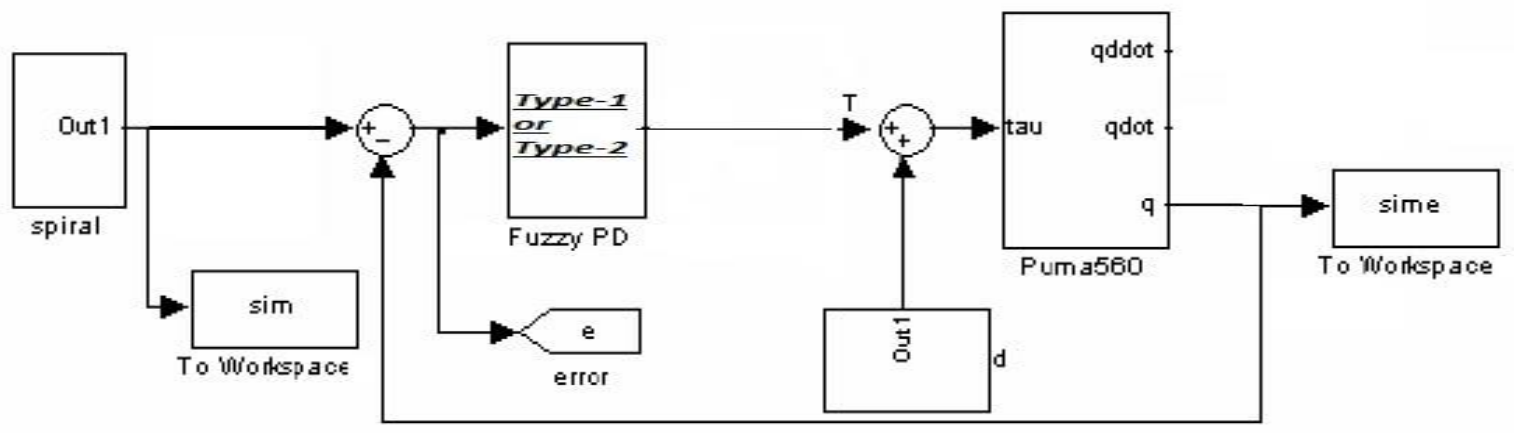

Figure 1. General diagram for fuzzy sets using in control of Puma560

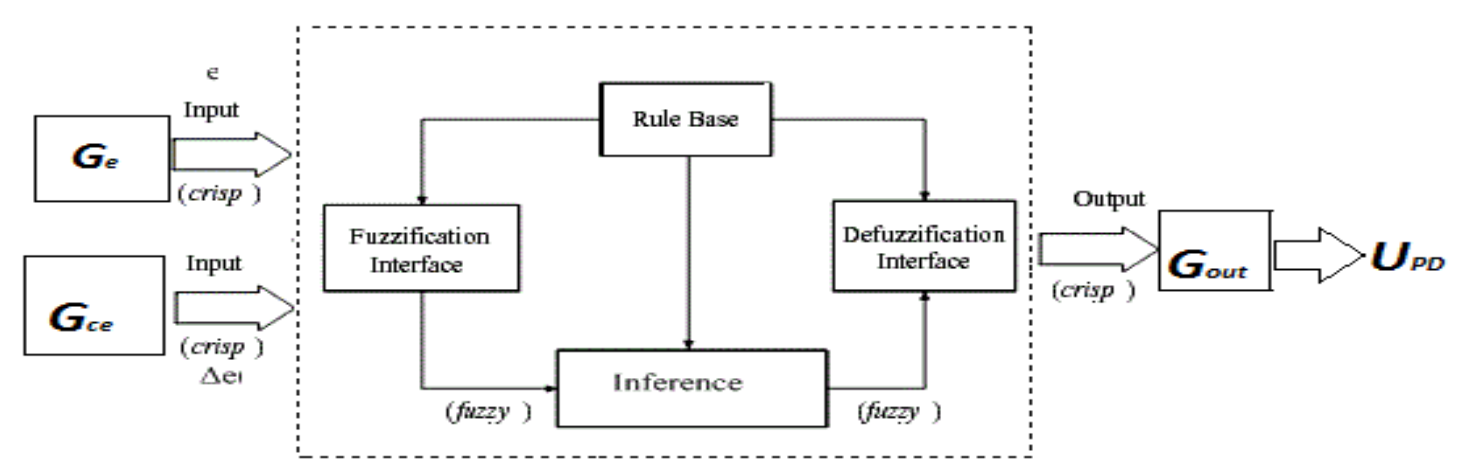

Figure 2. A type-1 fuzzy controller [4]

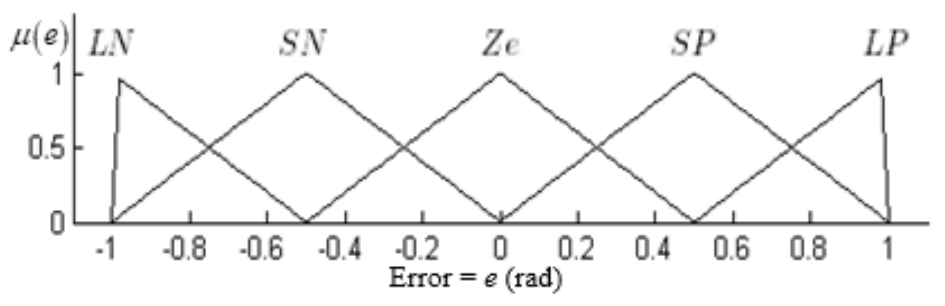

Figure 3. Fuzzy set for each articulation with triangle membership functions for error and its change 
Table 1. Rulebase table [7]

\begin{tabular}{|c|c|c|c|c|c|c|}
\hline \multicolumn{9}{|c|}{ Velocity error } \\
\hline \multirow{4}{*}{ Position error } & & N-L & N-S & Ze & P-S & P-L \\
\cline { 2 - 7 } & N-L & NL & NL & NL & NS & Ze \\
\cline { 2 - 6 } & N-S & NL & NL & NS & Ze & PS \\
\cline { 2 - 6 } & Ze & NL & NS & Ze & PS & PL \\
\cline { 2 - 6 } & P-S & NS & Ze & PS & PL & PL \\
\cline { 2 - 6 } & P-L & Ze & PS & PL & PL & PL \\
\hline
\end{tabular}

\section{CONTROLLERTYPE-2 FUZZY SETS}

The strategy of fuzzy logic does not vary from type-1 to interval-type-2 fuzzy sets [4, 6, 14-15]. A higher-type number just indicates a higher "degree of fuzziness". General diagram of interval fuzzy system is shown in Fig.4. Since a higher type changes the nature of the membership functions are themselves fuzzy $[4,16]$, the operations $[14,17]$ that depend on the membership functions change; however, the basic principles of fuzzy logic are independent of the nature of membership functions and hence, do not change.

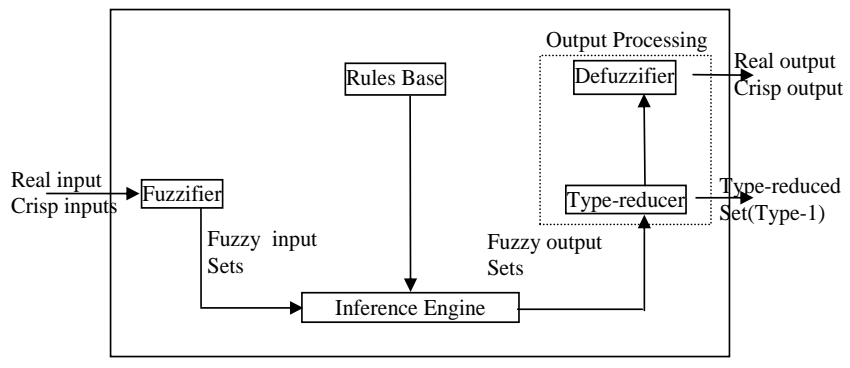

Figure 4. Interval type-2 fuzzy system diagram [4, 15- 16]

The configuration of the interval-type-2 fuzzy rules base [4, $6,15,18-19$ ] is the same as for the type-1 case [7]. In order to make distinction between interval-type-2 and type-1 fuzzy controllers, the nature of the membership functions used in the former are interval-type-2 fuzzy sets as illustrated in Figure 6. In a type-1 fuzzy system, where the output sets are type-1 fuzzy sets, we perform defuzzification in order to get a number, which is in some sense a crisp (type-0) representative of the combined output sets $[4,6,10]$. In the interval-type-2 fuzzy system case, the output sets are interval-type-2 fuzzy set $[4,6$, 20], so we have to use extended versions of type-1 fuzzy set defuzzification methods. Since type-1 fuzzy set defuzzification gives a crisp number at the output of the fuzzy system, the extended defuzzification operation in the intervaltype-2 fuzzy system case gives a type-1 fuzzy set at the output. Since this operation changes the interval type- 2 output sets of the fuzzy system to a type-1 fuzzy set, we can call this process "type reduction" [6, 21-22]. The type-reduced fuzzy set may then be defuzzified to get a single crisp number; however, in many applications, the type-reduced set may be more important than a single crisp number [14-15].

The general structure of an interval-type-2 fuzzy controller is represented in Figure 3. This diagram is similar to that of the type-1 fuzzy controller. However, their main differences are $[4,14-15]:$

- The type-1 membership functions are shown in Figure 3 but in interval-type-2 fuzzy sets they have lower and upper membership functions, as illustrated in Figure 6.
- In an interval type-2 fuzzy controller, a block of reduction of the type [6,21-22] is essential to convert the interval-type2 fuzzy set to a type-1 fuzzy set as indicated in Figure 4.

There exist many kinds of type-reduction methods, such as centroid, center-of-sets, height and modified height; the details of each are given in $[4,14,22]$. Uncertainty in the primary memberships of an interval-type-2 fuzzy set consists of a bounded region that we call the footprint of uncertainty (FOU) $[18,19]$ illustrated, as shaded region, in Figure 6 . The shaded FOUs imply that there is fuzzy degree of membership function of interval-type-2 fuzzy sets.

In this work, for illustrative purposes, we have use KarnikMendel algorithm of Figure 5 to locate Centroid on Interval type-2 fuzzy set [21]. The proposed modification is carried out in the fourth step of this algorithm where Karnik-Mendel use arithmetic mean, but in the presented work it has been modified by a harmonic mean, as in the next formulate:

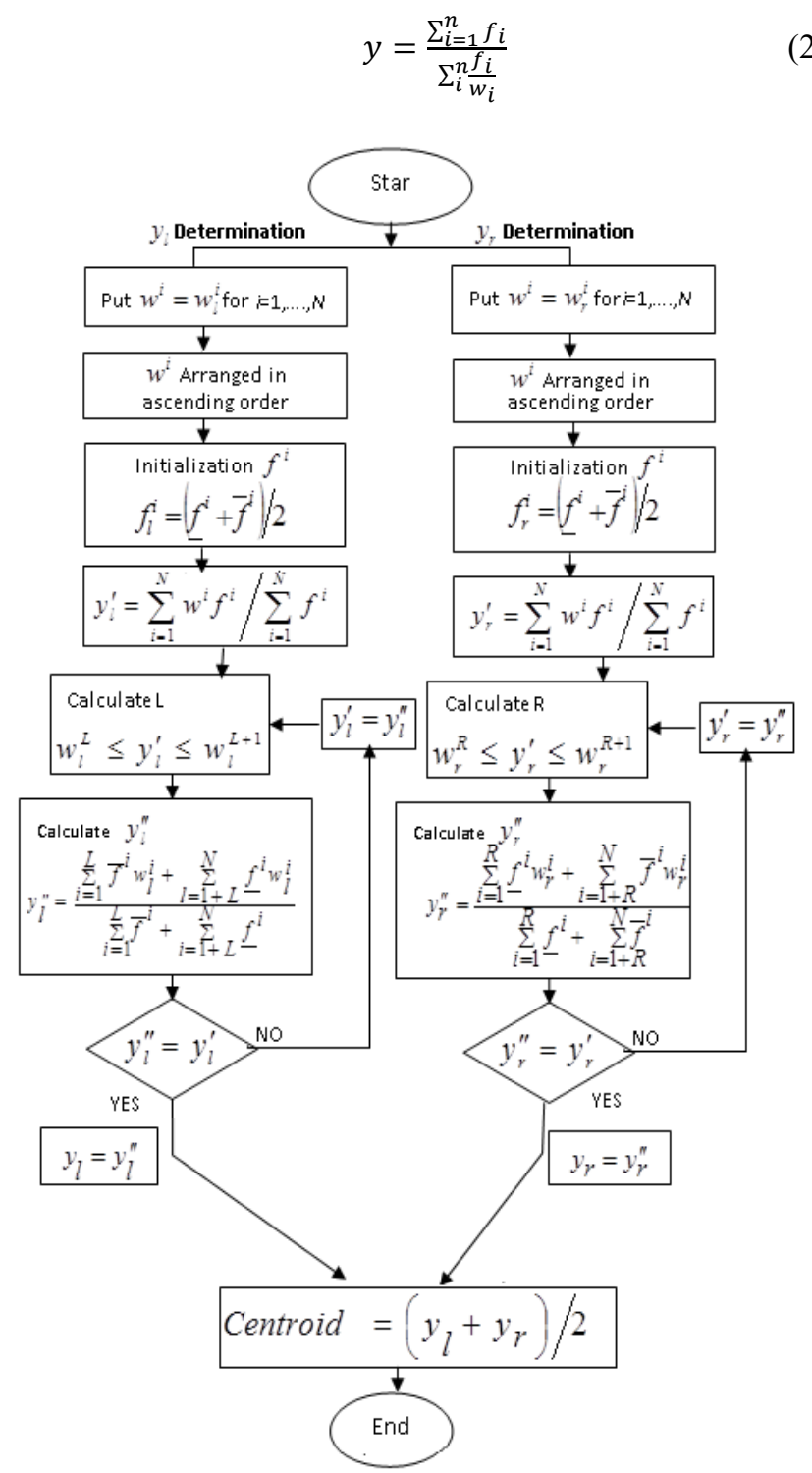

Figure 5. Karnik-Mendel algorithm to locate the centroid of interval type-2 set [21]

\section{SIMULATION RESULTS}

For our model of equation (1) 3DOF PUMA560 robot, a cycloid trajectory test Figure 7 used the different articulation 
move respectively from position $\left(-50^{\circ},-135^{\circ}, 135^{\circ}\right)$ to the position $\left(45,-85^{\circ}, 30^{\circ}\right)$ with three end time of movement equal to $(1.5,4,8)$ seconds then will have three cycloid trajectory are differ in simulation time. This trajectory is described by the following equation:

$$
\theta_{d i}=\left\{\begin{array}{c}
\theta_{d i}(0)+\frac{D_{i}}{2 \pi}\left[2 \pi \frac{t}{t_{\text {end }}}-\sin \left(2 \pi \frac{t}{t_{\text {end }}}\right)\right] \text { for } 0 \leq t \leq t_{\text {end }} \\
\theta_{d i}\left(t_{\text {end }}\right) \quad \text { for } \quad t_{\text {end }} \prec t \\
D_{i}=\theta_{d i}\left(t_{\text {end }}\right)-\theta_{d i}(0)
\end{array}\right.
$$

Integral of Square Error (ISE) [8] is used as performance index in comparative study between type-1 and interval-type2 fuzzy controller

$$
I S E=\int_{0}^{t_{\text {end }}}[e(t)]^{2} d t
$$

In type-1 fuzzy PD controller of Figure 2, fuzzy sets parameters take standard parameters as declared by default in MATLAB in the range of $[-1,1]$; the triangle membership functions are symmetric fuzzy sets. The controller requires three gains: two inputs gains and one output gain; these gains are chosen using manual tuning until getting good positions responses with lower error, lower control energy and smooth control signal without chattering in ideal case.

In an Interval-type-2 fuzzy PD controller, the interval-type2 fuzzy sets are programmed as type-1 fuzzy sets in the range of $[-1,1]$ with upper and lower triangle membership functions as shown in Figure 6. In addition to the length of FOU zone, the controller has also three gains to be designed: two inputs gains and one output gain. These gains and the FOU zone are chosen base on trial and error method until getting good positions responses with lower error, lower control energy and smooth control signal without chattering in ideal case.

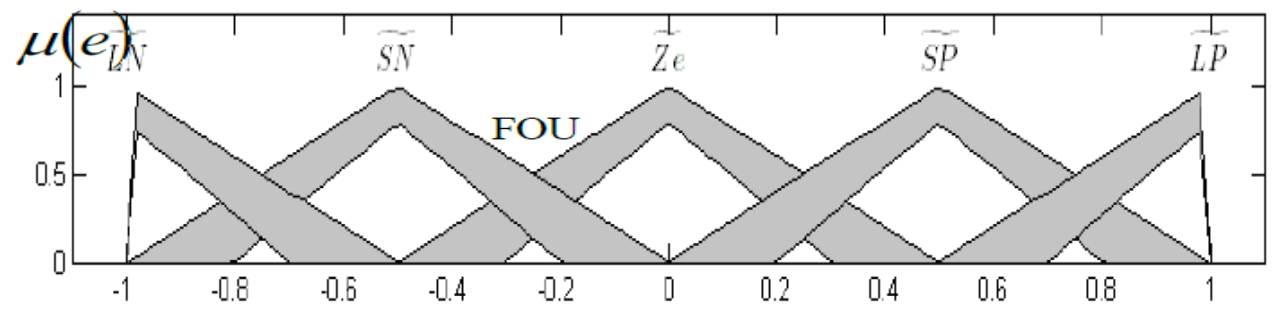

Figure 6. Fuzzy sets interval type-2 for each articulation and control signal
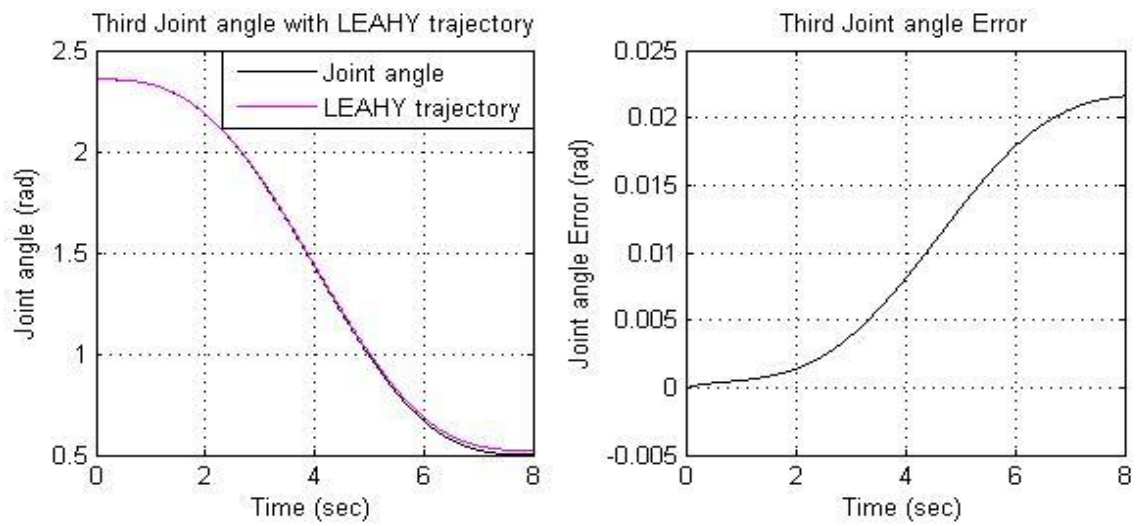

Figure 7. Third joint response to cycloid trajectory with noise and its tracking joint error
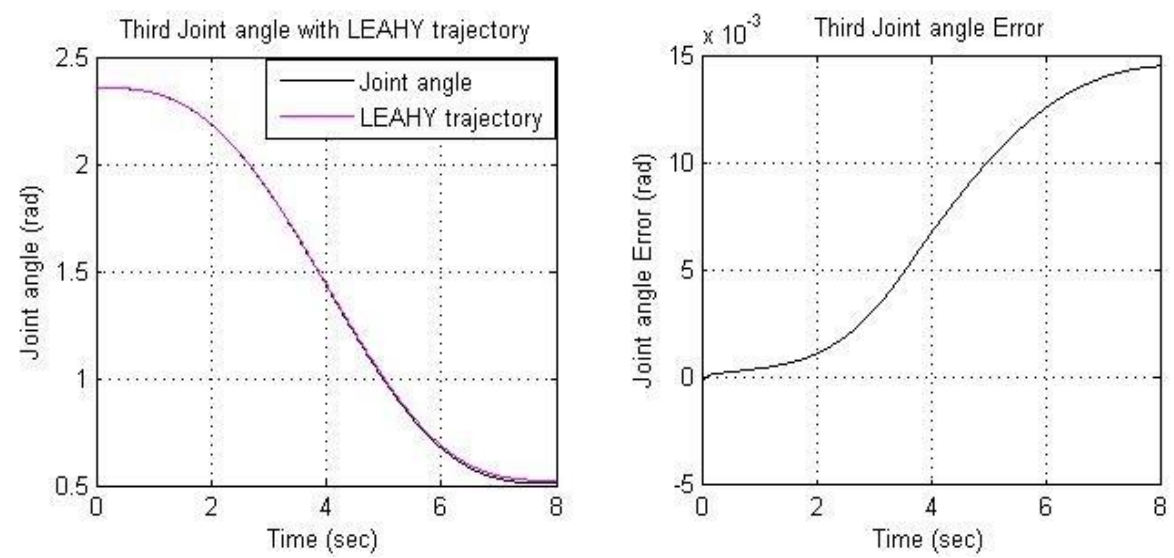

Figure 8. Third joint response with noise and its tracking joint error with modified type-reduction 
In order to verify the robustness of the proposed controller and to help us to achieve clear full comparison between type1 fuzzy controller and interval-type- 2 fuzzy controller and to see the ability each one in handling uncertainties, two kinds of noises are adopted: the first noise torque is $d=\sin (3 t)+1$ and the second noise torque is considered by taking $30 \%$ of joint torque for each joint.

The simulation results are devoted to show comparisons in the robot's responses when using both type-1 fuzzy controller and interval type- 2 fuzzy controller. A set of three simulations in each one three cycloid trajectories are adopted by changing end time with (1.5second, $4 \mathrm{~s}, 8 \mathrm{~s})$. We start with type-1 fuzzy controller in ideal conditions without any kind of disturbances. The values of ISE of three joint angles for three trajectories are gathered in Table 2. Figure 7 shows the response obtained by using type-1 fuzzy controller with presence of the noise torque taking $\mathrm{d}=30 \%$ of the torque control added as noise to the main control torque to check the robustness of controller. Figure 8 shows the response of the interval type- 2 fuzzy controller using modified type-reduction of Karnik-Mendel algorithm.

Comparison in terms of integral squared joint errors in ideal and disturbance cases $(\mathrm{d}=\sin (3 \mathrm{t})+1)$ is shown in Table 2 . Table 3 represents comparison in terms of integral squared joint errors in ideal and disturbance $\mathrm{d}=30 \%$ of joint signal control. The last column in Tables 2 and 3 is the factor (ISE_F) between the integral square joint error produced by using type1 fuzzy controller (ISE_T1) and integral square error produced by using of interval type-2 fuzzy controller (ISE_IT2) in noisy case, calculated as (5):

$$
I S E \_F=I S E_{-} T 1 / I S E_{-} I T 2
$$

This factor gives an idea in how many energies of error in type-1 fuzzy set is bigger than energy error of interval type- 2 fuzzy set case.

\section{RESULTS DISCUSSION}

The membership functions of type-1 fuzzy controller are type-1 fuzzy sets, see Figure 3, and their membership degrees are crisp values.

Table 2. ISE for different trajectory without and with disturbance $d=\sin (3 t)+1$

\begin{tabular}{|c|c|c|c|c|c|c|}
\hline & & \multicolumn{2}{|c|}{ ISE Type-1* } & \multicolumn{2}{|c|}{ ISE Interval type-2* } & \multirow{2}{*}{ ISE_F } \\
\hline Second & Joint & Nod & with d & No d & with d & \\
\hline \multirow{3}{*}{1.5} & J1 & 1.88 & 2.35 & 0.49 & 0.70 & 3.38 \\
\hline & $\mathrm{J} 2$ & 7.14 & 8.33 & 5.96 & 3.75 & 2.22 \\
\hline & $\mathrm{J} 3$ & 6.06 & 8.27 & 5.76 & 5.67 & 1.46 \\
\hline \multirow{3}{*}{4} & J1 & 0.23 & 0.54 & 0.24 & 0.15 & 3.49 \\
\hline & $\mathrm{J} 2$ & 32 & 36.9 & 18.71 & 16.84 & 2.19 \\
\hline & $\mathrm{J} 3$ & 19.7 & 30.2 & 17.48 & 24.91 & 1.21 \\
\hline \multirow{3}{*}{8} & J1 & 0.043 & 0.64 & 0.02 & 0.26 & 2.44 \\
\hline & $\mathrm{J} 2$ & 83.5 & 94 & 31.88 & 50.80 & 1.85 \\
\hline & $\mathrm{J} 3$ & 54 & 81 & 46.63 & 50.21 & 1.61 \\
\hline
\end{tabular}

Table 3. ISE for different trajectory without and with disturbance in joint control $d=30 \%$ of each joint

\begin{tabular}{ccccccc}
\hline & & \multicolumn{2}{c}{ ISE Type-1* } & \multicolumn{2}{c}{ ISE Interval type-2* } & \multirow{2}{*}{ ISE_F } \\
\cline { 1 - 6 } Second & Joint & No d & with d & Nod & with d & \\
\hline \multirow{2}{*}{$1.5 \mathrm{~s}$} & J1 & 1.88 & 4.23 & 0.50 & 0.91 & 4.63 \\
& J2 & 7.14 & 19.1 & 3.88 & 7.28 & 2.62 \\
& J3 & 6.06 & 14.8 & 5.63 & 9.09 & 1.63 \\
\hline \multirow{3}{*}{$4 \mathrm{~s}$} & J1 & 0.23 & 0.48 & 0.23 & 0.13 & 3.77 \\
& J2 & 0.32 & 79.3 & 22.44 & 38.94 & 2.04 \\
& J3 & 19.7 & 44.7 & 12.16 & 23.80 & 1.88 \\
\hline \multirow{2}{*}{$8 \mathrm{~s}$} & J1 & 0.043 & 0.091 & 0.02 & 0.03 & 2.72 \\
& J2 & 83.5 & 200 & 43.78 & 80.08 & 2.50 \\
& J3 & 54 & 120 & 44.37 & 79.28 & 1.51 \\
\hline
\end{tabular}

Note: *all values are multiplied by $10^{-5}$

Interval type-2 fuzzy controller has FOU zone in which the membership degrees are an interval and not crisp values. Actually, this is the main part that improves the degree of dealing with uncertainties. In an interval-type-2 fuzzy controller, the outputs of the inference are interval-type-2 sets and a type-reducer is needed to convert them into a type- 1 sets before defuzzification to generate a crisp output. This is the main structural difference between type-1 and interval-type-2 fuzzy systems. In Table 4, some differences between type-1 fuzzy controller and interval type-2 fuzzy controller are given.

When comparing results based on visual observation, the actual and desired joint angles are overlapping without tangible difference as illustrated in Figure 7. But in terms of ISE values it is possible to measure the difference between the two fuzzy controllers. To perform this comparison, three simulations with different simulation times are realized, which give us three different trajectories for three robot joints with two disturbance torques to test robustness. All results are sum up in two tables; Table 2 for comparison between type-1 fuzzy controller and modified interval type- 2 fuzzy controller with disturbance $d=\sin (3 t)+1$ and Table 3 for comparison between type-1 fuzzy controller and modified interval type-2 fuzzy controller with disturbance $d=30 \%$ of control torque. It is very clear that average of ISE_F column around two times that means the tracking error angle for type-1 fuzzy controller is bigger two times than error angle for modified interval-type-2 fuzzy controller.

Finally when comparing all results in all figures, Table 2, 
and Table 3, it is very clear that interval-type-2 fuzzy controller is better than type-1 fuzzy controller in ideal or in noises cases.

Table 4. Some differences between type-1 and intervaltype-2 fuzzy controller

\begin{tabular}{ccc}
\hline & T1-FS & IT2-FS \\
\hline Grades of membership & Crisp & Fuzzy \\
footprint of uncertainty zone & Don't have & Have \\
Type-reducer & Don't need & Need \\
Computational & Small & Little Large \\
Program & Easy & Little Hard \\
\hline
\end{tabular}

\section{CONCLUSION}

This paper presents a comparative study between type- 1 and interval type-2fuzzy logic controllers of 3DOF PUMA560. Three simulations for three robot joints with and without noises are presented. Furthermore, a quantification of errors was achieved and documented in tables for integral square error of trajectory tracking. It was shown that the lower errors were obtained using an interval-type-2 fuzzy controller where the amount of error are four times less than using a type-1 fuzzy set to control a manipulator robot. Interval-type-2 fuzzy controller is much better because it can handle uncertainties and have robustness than type-1 fuzzy counterpart. Also, the proposed modification in type reduction of Karnik-Mendel algorithm by using harmonic mean performs better than arithmetic mean used in the traditional Karnik-Mendel algorithm.

Future works will be devoted to the implementation of an interval type-2 fuzzy controller of PUMA560 robot with fuzzy set parameters optimization. Hybridization of interval type-2 fuzzy controller with other robust controllers is another idea worth to be explored.

\section{REFERENCES}

[1] Dombre, E., Khalil, W. (2004). Modeling, identification and control of robots. Kogan Page Science. London, United Kingdom. https://doi.org/10.1016/B978-1903996-66-9.X5000-3

[2] Craig, J.J. (1982). Introduction to robotics. mechanics and control. 2nd, Addison-Wesley. Boston, United States of America.

[3] Zadeh, L. (1975). The concept of a linguistic variable and its application to approximate reasoning. Information Science, 8(3): 199-249. https://doi.org/10.1016/00200255(75)90036-5

[4] Castillo, O., Melin, P. (2008). Type-2 fuzzy logic: Theory and applications. Springer-Verlag. Heidelberg, Germany.

[5] Adam, F., Hassan, N. (2017). Group decision making methods based on multi Q-fuzzy soft interval set. Malaysian Journal of Mathematical Sciences, 11(1): 5370.

[6] Liang, Q., Mendel, J.M. (2000). Interval type-2 fuzzy logic systems: Theory and design. IEEE Trans. Fuzzy Syst, 8(15): 535-550. https://doi.org/10.1109/91.873577

[7] Khoury, G.M., Saad, M., Kanaan, H.Y. (2004). Fuzzy PID control of a five DOF robot arm. Journal of Intelligent and Robotic Systems, 40: 299-320.
https://doi.org/10.1023/B:JINT.0000038947.97195.22

[8] Kumar, A., Kumar, V. (2017). Evolving an interval type2 fuzzy PID controller for the redundant robotic manipulator. Expert Systems with Applications, 73: 161177. https://doi.org/10.1016/j.eswa.2016.12.029

[9] Zakeri, E., Farahat, S., Moezi, S.A., Zare, A. (2016). Path Planning for unmanned underwater vehicle in $3 \mathrm{D}$ space with obstacles using Spline-Imperialist competitive algorithm and optimal interval type-2 fuzzy logic controller. Latin American Journal of Solids and Structures, 13(6): 1054-1085. http://dx.doi.org/10.1590/1679-78252029

[10] Wu, D. (2012). On the fundamental differences between interval type-2 and type-1 fuzzy logic controllers. IEEE Transactions on Fuzzy Systems, 20(5): 832-848. https://doi.org/10.1109/TFUZZ.2012.2186818

[11] Gaidhane, P.J., Nigam, M.J., Kumar, A., Pradhan, P.M. (2019). Design of interval type-2 fuzzy precompensated PID controller applied to two-DOF robotic manipulator with variable payload. ISA Transactions, 89: 169-185. https://doi.org/10.1016/j.isatra.2018.12.030

[12] Kelekci, E., Kizir, S. (2019). Trajectory and vibration control of a flexible joint manipulator using interval type2 fuzzy logic. ISA Transactions. In press. https://doi.org/10.1016/j.isatra.2019.04.001

[13] Sepuilveda, R., Castillo, O., Melin, P., Rodriguez-Diaz, A., Montiel, O. (2005). Integrated development platform for intelligent control based on type-2 fuzzy logic. Fuzzy Information Processing Society. Annual Meeting of the North American, 607-610. https://doi.org/10.1109/NAFIPS.2005.1548606

[14] Armstrong, B., Khatib, O., Burdick, J. (1986). The explicit dynamic model and inertial parameters of the PUMA 560 arm. in IEEE Int. Conf on Robotics and Automation, San Francisco, USA, pp. 510-518. https://doi.org/10.1109/ROBOT.1986.1087644

[15] Iancu, I., Mamdani, A. (2012). Type fuzzy logic controller. Romania, University of Craiova: http://www.intechopen.com/books/fuzzy-logic-controlsconcepts-theories-and-applications/a-mamdani-typefuzzy-logic-controller.

[16] Mendel, J.M. (2000). Uncertainty, fuzzy logic, and signal processing. Signal Processing, 80(6): 913-933. https://doi.org/10.1016/S0165-1684(00)00011-6

[17] Karnik, N.N., Mendel, J.M. (1998). An introduction to type-2 fuzzy logic Systems. Univ. Southern California, California.

[18] Mendel, J.M., Robert, I.J. (2003). Type-2 fuzzy sets: Some questions and answers. IEEE Connections, Newsletter of the IEEE Neural Networks Society, 1: 1013.

[19] Karnik, N.N., Mendel, J.M., Liang, Q. (1999). Type-2 fuzzy logic systems. IEEE Trans. Fuzzy Systems, 7(16): 643-658. https://doi.org/10.1109/91.811231

[20] Mendel, J.M. (1995). Fuzzy logic systems for engineering: A tutorial. IEEE transactions on Fuzzy Systems, 2(11): 345-377. https://doi.org/10.1109/5.364485

[21] Nilesh, N.K. (1998). Type-2 fuzzy logic systems. PhD Dissertation, University of Southern, California.

[22] Mendel, J.M., Robert, I.J. (2001). A fundamental decomposition of type-2 fuzzy sets. Univ. Southen California, Univ. De Montfort, United Kingdom.

[23] Mendel, J.M., Hongwei, W. (2007). New results about 
the centroid of an interval type-2 fuzzy set, including the centroid of a fuzzy granule. Information Sciences, 177(2): 360-377. https://doi.org/10.1016/j.ins.2006.03.003

[24] Qilian, L. (2000). Fading channel equalisation and video traffic classification using nonlinear signal pressing techniques. PhD Dissertation, University of Southern California.

[25] Karnik, N.N., Mendel, J.M. (1998). Type-2 fuzzy logic systems: Type-Reduction. IEEE SMC Conference, San Diego. https://doi.org/10.1109/ICSMC.1998.728199

\section{APPENDIX}

Matrix $\mathrm{M}$ is a symmetric $3 \times 3$ matrix:

$$
M(q)=\left[\begin{array}{lll}
a_{11} & a_{12} & a_{13} \\
a_{21} & a_{22} & a_{23} \\
a_{31} & a_{32} & a_{33}
\end{array}\right]
$$

where,

$$
\begin{gathered}
a_{11}=I_{m 1}+I_{1}+I_{3} \cdot C C 2+I_{7} \cdot S S 23+I_{10} \cdot S C 23+ \\
I_{11} \cdot S C 2+2 \cdot\left[I_{5} \cdot C 2 \cdot S 23\right] \\
a_{12}=I_{4} \cdot S 2+I_{8} \cdot C 23+I_{9} \cdot C 2 \\
a_{13}=I_{8} \cdot C 23 \\
a_{22}=I_{m 2}+I_{2}+I_{6}+2 \cdot\left[I_{5} \cdot S 3\right] \\
a_{23}=I_{5} \cdot S 3+I_{6} \\
a_{33}=I_{m 3}+I_{6} \\
a_{21}=a_{12}, a_{31}=a_{13} \text { and } a_{32}=a_{23}
\end{gathered}
$$

While matrix B is:

$$
B(q)=\left[\begin{array}{ccccccc}
b_{112} & b_{113} & 0 & 0 & 0 & b_{123} & 0 \\
0 & 0 & 0 & 0 & 0 & b_{223} & 0 \\
0 & 0 & 0 & 0 & 0 & 0 & 0
\end{array}\right]
$$

where,

$$
\begin{gathered}
b_{112}=2 \cdot\left[-I_{3} \cdot S C 2+I_{5} \cdot C 223+I_{7} \cdot S C 23\right] \\
+I_{10} \cdot(1-2 \cdot S S 23)+I_{11} \cdot(1-2 \cdot S S 2) \\
b_{113}=2 \cdot\left[I_{5} \cdot C 2 \cdot C 23+I_{7} \cdot S C 23-\right]+I_{10} \cdot(1-2 \cdot S S 23) \\
b_{123}=2 \cdot\left[-I_{8} \cdot S 23\right]
\end{gathered}
$$

Matrix $\mathrm{C}$ is:

$$
C(q)=\left[\begin{array}{ccc}
0 & c_{12} & c_{13} \\
c_{21} & 0 & c_{23} \\
c_{31} & c_{32} & 0
\end{array}\right]
$$

where,

$$
\begin{gathered}
c_{12}=I_{4} \cdot C 2-I_{8} \cdot S 23-I_{9} \cdot S 2 \\
c_{13}=0.5 \cdot b_{123}=-I_{8} \cdot S 23 \\
c_{21}=-0.5 \cdot b_{112}=I_{3} \cdot S C 2-I_{5} \cdot C 223-I_{7} \cdot S C 23- \\
0.5 . I_{10} \cdot(1-2 . S S 23)-0.5 \cdot I_{11} \cdot(1-2 \cdot S S 2) \\
c_{23}=0.5 \cdot b_{223}=I_{5} \cdot C 3 \\
c_{31}=-0.5 \cdot b_{113}=-I_{5} \cdot C 2 \cdot C 23-I_{7} \cdot S C 23 \\
-0.5 \cdot I_{10} \cdot(1-2 \cdot S S 23) \\
c_{32}=-c_{23}=-I_{5} \cdot C 3
\end{gathered}
$$

And matrix $\mathrm{G}$ is:

$$
\begin{gathered}
g(q)=\left[\begin{array}{l}
0 \\
g_{2} \\
g_{3}
\end{array}\right] \\
g_{2}=g_{1} \cdot C 2+g_{2} . S 23+g_{3} \cdot S 2 \\
g_{3}=g_{2} . S 23
\end{gathered}
$$

where,

$S i=\sin (\theta i), C i=\cos (\theta i), C i j=\cos (\theta i+\theta j), \operatorname{Sijk}=\sin (\theta i+\theta j$ $+\theta k)$, with $i=1,2,3$.

Table 5. Inertial constants $\left(\mathrm{kg} \cdot \mathrm{m}^{2}\right)[9]$

\begin{tabular}{|l|l|}
\hline$I_{1}=1.43 \pm 0.05$ & $I_{2}=1.75 \pm 0.07$ \\
\hline$I_{3}=1.38 \pm 0.05$ & $I_{4}=0.69 \pm 0.02$ \\
\hline$I_{5}=0.372 \pm 0.031$ & $I_{6}=0.333 \pm 0.016$ \\
\hline$I_{7}=0.298 \pm 0.029$ & $I_{8}=-0.134 \pm 0.014$ \\
\hline$I_{9}=0.0238 \pm 0.012$ & $I_{10}=-0.0213 \pm 0.0022$ \\
\hline$I_{m 1}=1.14 \pm 0.27$ & $I_{m 2}=4.71 \pm 0.54$ \\
\hline$I_{m 3}=0.827 \pm 0.093$ & \\
\hline
\end{tabular}

Table 6. Gravitational constants (N.m) [9]

\begin{tabular}{|l|l|}
\hline$g_{1}=-37.2 \pm 0.5$ & $g_{2}=-8.44 \pm 0.20$ \\
\hline$g_{3}=1.02 \pm 0.50$ & \\
\hline
\end{tabular}

Tables 5 and 6 contain the computed values for the constants appearing in the equations (1). 